\title{
Example of intermediate care: the new Lambeth Community Care Centre
}

\author{
ROGER HIGGS
}

Pressure on the British health service in the past decade has led to many difficult decisions. In several areas small or peripheral hospitals have been closed to centralise secondary care and reduce expenditure. In 1976 the Lambeth Hospital was one of the first casualties of what has since become a national trend. Yet on 20 November 1985 the Prince and Princess of Wales will visit the site of the original hospital to celebrate the opening of a new small unit in south London that represents a step forward in health care appropriate to urban areas. In this environment there are many patients whose conditions need the skills of the medical or nursing generalist but who for lack of home care, community support, or adequate preventative measures end up on a specialist hospital ward not designed for their needs. For such patients this experience may be difficult and even dangerous, for their carers it is often frustrating and demotivating, and for the health service it is usually expensive and wasteful. Health care in the 1980s should provide a more appropriate and economic response, which at the same time enables the resources of the neighbouring hospital to be used more effectively. One answer to this, combining the innovative with the traditional, is the new Lambeth Community Care Centre.

Lambeth Community Care Centre, London SE11

ROGER HIGGS, MRCP, MRCGP, general practitioner and chairman of Lambeth Community Care Centre project team

Other members of Lambeth Community Care Centre project and management teams: Sandy Clarke, Edward Cullinan, Steven Curson, Maureen Dillon, Nigel Draper, Jean Fairs, Sue Freudenberg, Audrey Llewellyn, William Marson, Robin Nicholson, David Poole, Jenny Potter, Keith Sherlock, Roger Smiles, Mungo Smith, Graham Soper, Sheila Woodward.

\section{Intermediate care in the city}

The need for intermediate care exists everywhere but has been felt most sharply in the inner city areas where poverty and deprivation are the rule. Provision of hospitals here has in the past been most generous, with many founded originally to serve the local poor. Some of these hospitals have now obtained international reputations as centres of excellence in teaching and research but at some cost to their original aims. Until recently it has been left to the smaller city hospitals to provide cover for the underfunded community and general practitioner services, while the larger and more central hospitals have developed district specialist and regional and national supraspecialist responsibilities. With the multiple financial pressures of national and regional redistribution of resources most smaller units have now been closed, but the attempt to cover this loss by transferring funding from acute curative services to the community and preventive and long term care is easily frustrated and its effectiveness, by definition, difficult to show in the short term.

This gap in care in organisational terms is mirrored by a gap in appropriate clinical skills. The general physician is now difficult to find, and the general practitioner's medical expertise may be eroded by the heavy pressure of psychosocial problems in inner city surgeries. In some districts the rules governing district nurses have become tighter, their roles more restricted. Health visitors and overburdened social service departments are forced to concentrate on children and young families, to the detriment of other priority groups. Some of these health workers may be just like the people that need their services-isolated, poorly resourced, and badly housed. Meanwhile, the districts in which they work are being asked to take on the care of new patients with major handicaps leaving long stay hospitals, and the statistics of many maje but potentially preventable medical conditions in lower socioeconomic groups are worsening. In practice, a ton of acute misery outweighs an ounce of prevention, whatever scales are used.

Elsewhere voluntary and lay help may make up for some of these deficiencies in the health service. In the city, however, necessary rehousing schemes have often destroyed close neighbourhoods and weakened community initiative. Younger people with "get up and go" have done just that. Neighbours may be strangers, and visitors by definition are up to no good. High rise housing schemes of the past decade have left the elderly isolated on the upper floors, while the ground level is the territory of the car and the street criminal. Telephones are expensive, and few people will answer a knock on their doors after dark. Thus domiciliary care schemes are difficult to 
maintain. In our cities many people have worked hard, individually or in groups, to reverse these trends and provide care and cover under increasing difficulties. Nevertheless, brave communities with fewer resources than ever are being asked to take on more cases of illness and handicap. The trickle of need for intermediate care has become a flood.

\section{Lambeth Community Care Centre}

In south London the closing of the Lambeth Hospital stimulated the West Lambeth Community Health Council to follow David Owen's advice, as health minister, to look again at the alternative of the smaller or community hospital. Local residents and primary care workers were contacted, individually and by surveys. Community groups were interested and en thusiastic, and help was forthcoming within the National Health Service from local general practitioners and forward thinking consultants, academics, and health service planners. Cottage hospitals in the country and day centres in cities were visited as potential models. The Inner City Partnership scheme provided the possibility of finance, and the long process of proposal, modification, application, and reapplication to the three layered health service took place. All those who have been concerned in such a campaign will know how it can be in turn exciting, exhausting, bitterly disappointing, and often very funny. A multidisciplinary project group developed cohesion and understanding from these endeavours.

In 1981 the district finally approved plans for an adult unit consisting of 20 beds and 35 day places with facilities for health education and contact for both local people and primary health care workers. The inpatients' facilities were planned for the postoperative, the dying, those requiring acute but not specialised medical care, and the disabled whose carers needed periodic relief. The day unit was to care for a similar range of patients, in addition to those with problems of mobility and daily living requiring specific and skilled occupational therapy or physiotherapy. The aim was always to preserve the best of home care in terms of atmosphere, comfort, and personal autonomy combined with the best of skilled nursing and appropriate therapy. The medical care was to be given by the patient's general practitioner in contract with the district. Space was to be provided for dentistry, chiropody, and speech therapy as well as for hairdressing, workshop facilities, and social and community link work.

This development demanded a special degree of shared commitment from the diverse members of the project team representing community, professional, and health service administrative groups. The brief that was developed, for a flexible domestic environment that could cope with professional use, also demanded a remarkable design team and preferably one completely new to health service building. We were very fortunate to find architects (Edward Cullinan Architects) who provided an intuitive and intelligent response and helped the project group define its concepts and procedures as well as establishing building requirements. For many members of the project team subjecting their professional aims and attitudes to shared scrutiny was an uncomfortable experience, but the rewards were great, and the enthusiasm generated created original thinking in health care and architecture.

\section{The initial months}

This degree of shared planning is one of the centre's claims to originality and has undoubtedly contributed to the success of the project in its first few months. The ideas discussed initiated similar ventures elsewhere in the city, but this centre is the first purpose built city community hospital linking the local community directly with its health care programme.

One of the centre's achievements has been to it. Normal routines of living are re-established create excitement and enthusiasm about groups of patients whose care has so often created the reverse. The aim is to fulfil potential not just to define pathology. Each area raises its own questions and requires practical answers. The emphasis on personal autonomy has meant that patients have the fullest possible access to their own notes, the plans and progress charts being at the bedside. Whenever possible they have control over and administer their own treatment and are concerned in making plans for their recovery and in shaping

19 Occupational therapy
20 Seminar room
21 Conservatory
22 Sitting area
23 Cloakroom
24 Dining
25 Servery
26 Cleaner
27 Male changing room


in this atmosphere with speed and to great effect-for instance, one patient, severely disorientated by a major stroke, made a sudden decisive improvement when he went outside in a wheelchair and discovered that he was on his own home territory. Provision of relief for patients' families has rapidly created a mutually supportive group in the community focused on the centre. Carers apparently about to throw in the sponge have taken it up again with determination. Some of this enthusiasm comes from the beauty of the building, some from the qualities and approach of the staff: it strikes all who visit. "I should like to live here," said a 13 year old visitor; "I should like to die here," said his younger sister. Discussion of dying showed the need for a place for relatives who have travelled a long distance to stay overnight in the centre, for rooms for spouses to share, for terminal care of patients with chronic as well as malignant diseases, and for an open policy about the handling of death within the centre.

Something of the peace as well as the hope of progress transmits itself to patients and relatives alike when communication is open and honest. One terminal patient's pain was rapidly controlled once a new trust and understanding of his illness was conveyed in discussion with his nurse. Another patient with multiple sclerosis, previously isolated at home, made rapid improvements in mobility and confidence with skilled treatment. In matters of mobilisation especially precision and care about small practical issues can often make a major difference to the patient's outcome and quality of life. Many of the skills of occupational therapists or physiotherapists are not usually part of the general practitioner's traditional options. A single woman who required support tights to prevent disabling venous ulceration had too severe arthritis to put them on. The occupational therapist's stocking gutter provided the answer. For the want of a nail file the battle had almost been lost.

\section{Continuing assessment and the future}

The quality and direction of the work of such an experiment must be assessed continually. New rules and roles have to be learnt, and the members of the project team, by informal discussion, formal case conferences, and regular audit meetings, are establishing the new pattern of care. A local advisory group consisting of lay people and staff working at the centre is being set up to examine policy and development. More formal assessment is needed to see if the objectives set in planning are being reached, what alternatives exist, and how this affects cost. Some questions are not easy to tackle. Even if we know the cost what is the true value of forestalling an admission to the local teaching hospital; preventing deterioration of a condition; or increasing a person's mobility, confidence, and independence? Arguments that depend only on cash must not be allowed to usurp discussion of care or we shall face the ultimate logic of continued economics in health care spending, the reductio ad absurdum of a minimalist service as ridiculous and damaging as the uncontrolled approach it shuns.

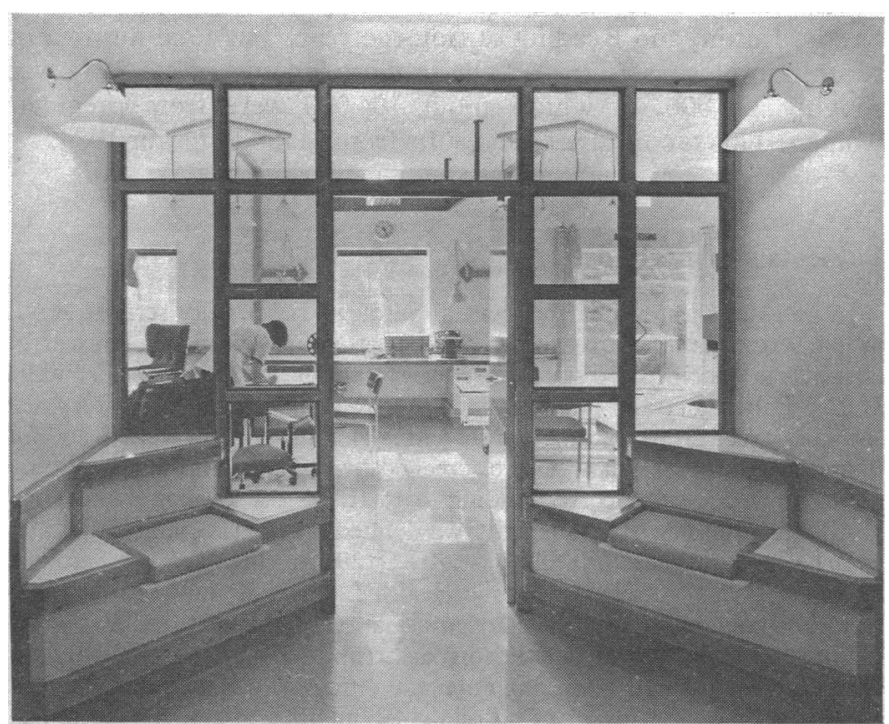

FIG 3-Corridors open up to doors and windows with corner seats as resting places.

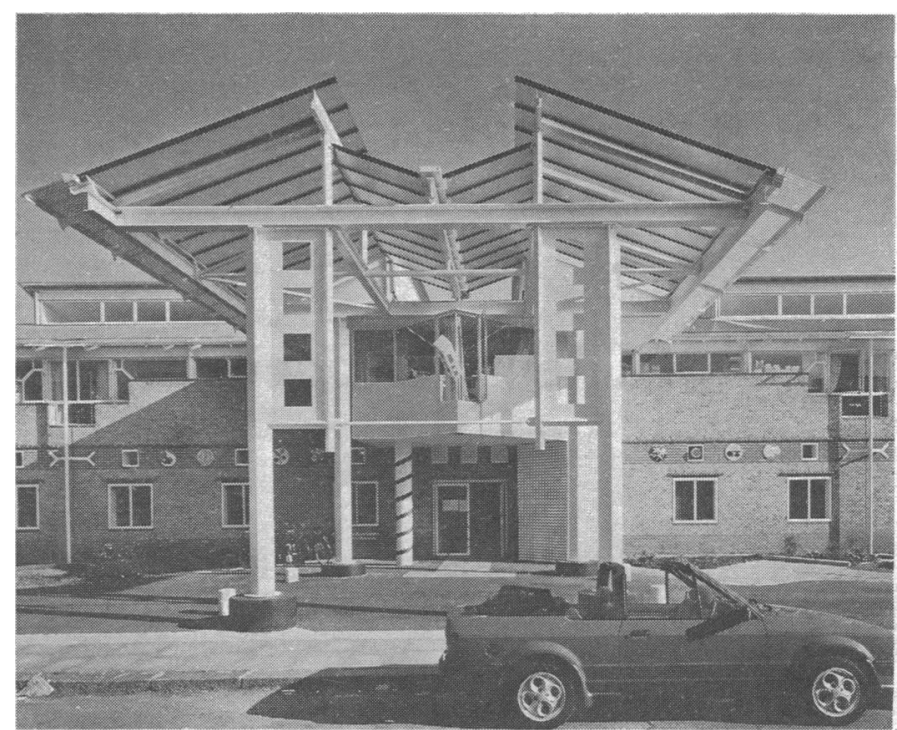

FIG 4-Front entrance with its canopy for ambulances.

Most objections raised in opposition to the centre's development have already been answered. We know that first class care can be provided in this setting. Practitioners will offer 24 hour cover, perform satisfactorily, and audit their performance. Admissions and discharges can be made appropriately and day centre and beds be used well, and recruitment and reorientation of suitable staff is not a problem. Visits have already been received from other workers with similar ideas from small units elsewhere whose future is under debate.

Thus the challenge of intermediate care is with us all. Do we provide or do we ignore? Is it appropriate care or chronic crisis? Starting from need this project team thinks it has defined a new type of response. Is this, however, the last gasp of the dying welfare state or perhaps just a brave idea, an original mutant, appearing out of time in an unreceptive world; or is it, as we believe, the pattern of something new and vital to be modified and adapted for the next decade?

Photographs by Martin Charles, courtesy of The Architects' Fournal. Visitors to the Centre (Monkton Street, London SE11) are welcome on specific days on a first come first served basis. Please ring the administrator, Jenny Potter, 015825513.

(Accepted 21 October 1985)

A woman of 30 underwent an ileojejunal bypass operation in 1981 for severe obesity. She has done well, returned to normal weight, and has regular biochemical tests for folate, vitamin $B_{12}$, and calcium levels. At her annual follow up appointment she was told that the operation had now been discontinued and that many patients have undergone reversal operations for severe sequelae. She was not told what these might be. What should I look out for?

Jejunoileal bypass became popular because it is an easy operation that usually succeeded in reducing weight by $30-40 \%$. Unfortunately long term complications are common and may be serious, so other procedures are taking its place. The main complications are: diarrhoea, foul flatus, abdominal bloating, oxolate kidney stones, arthritis, osteomalacia, skin inflammation, cholesterol gall stones, and fatty liver, sometimes leading to liver failure. In an asymptomatic patient biochemical liver function tests should be done as well as those listed in the question. A consistently high rising transaminase activity would be an indication for liver biopsy.- J BENNETT, consultant physician, Kingston upon Hull.

Bouchier IDA, Allan RN, Hodgson HJF, Keighley MRB, eds. Textbook of gastroenterology. London Baillière Tindall, 1984:530.

Garrow JS. Treat obesity seriously. London: Churchill Livingstone, 1981

Linner JH, ed. Surgery for morbid obesity. Berlin: Springer-Verlag, 1984.

Halverson JD, Scheff RJ, Gentry K, Alpers DH. Jejunoileal bypass. Late metabolic sequelae and weight gain. Am J Surg 1980;140:347-50. 